Research Article

\title{
Behavior Selection of Stakeholders toward Megaproject Social Responsibility: Perspective from Social Action Theory
}

\author{
Linlin Xie $\mathbb{D}^{1},{ }^{1}$ Ting Han, ${ }^{1}$ Haitao Chu $\mathbb{D},{ }^{2}$ and Bo Xia $\mathbb{D}^{3}$ \\ ${ }^{1}$ South China University of Technology, School of Civil Engineering \& Transportation, Guangzhou 510000, China \\ ${ }^{2}$ Tongji University, School of Economics and Management, Shanghai 200000, China \\ ${ }^{3}$ Queensland University of Technology, School of Civil Engineering and Built Environment, Brisbane 4001, Australia
}

Correspondence should be addressed to Haitao Chu; huddechu@tongji.edu.cn

Received 17 February 2019; Accepted 23 August 2019; Published 24 October 2019

Guest Editor: Endong Wang

Copyright (C) 2019 Linlin Xie et al. This is an open access article distributed under the Creative Commons Attribution License, which permits unrestricted use, distribution, and reproduction in any medium, provided the original work is properly cited.

\begin{abstract}
The importance of social responsibility strategy for the sustainable development of megaprojects has been widely concerned, while types and motivations of social responsibility behavior have also been analyzed and examined in the corporate management literature. However, the typical social responsibility behaviors in megaprojects and the various motivations and factors that influence stakeholders' selection of social responsibility behavior have not been fully considered and confirmed. In this study, camouflage behavior and collaborative behavior are taken as representative social responsibility behaviors. Based on the social action theory, the impact of relevant influencing factors is empirically examined and stakeholder's selection of these two behaviors toward megaproject social responsibility (MSR) is explored. Results from the sample data of 127 management staff with megaproject experience from the participating parties revealed that synergistic behavior is driven mainly by relationship quality (RQ), whereas hypocritical behavior is affected by RQ, institutional pressure, and external appeals. In addition, the mutual feedback mechanism significantly improves the RQ of participating parties, which indirectly affects both behaviors. These findings bear implications in realizing the management of social responsibility behavior in megaprojects and guiding the participating parties to coordinate and implement social responsibility.
\end{abstract}

\section{Introduction}

Megaproject social responsibility (MSR) refers to the obligation of megaproject participating parties on the social and environmental impacts of their decisions and activities through transparent and ethical behavior during the project life cycle $[1,3]$. Under the current emphasis on green development and social stability, megaprojects are increasingly prioritizing cross-integration with society [4], economy [5], culture [6], and ecology [7]. MSR is undoubtedly an important "value" element in measuring the success of engineering projects.

MSR is closely related to the behavior of stakeholders. Unlike the corporate social responsibility (CSR) of a single organization, MSR involves multiple participating parties, and the fulfillment of their social responsibilities requires engagement from a large number of other participating parties [8-10]. The lack, improperness, or alienation of any party's behavior toward responsibility may damage the investment efficiency and break the social image of the project and even lead to its termination [11, 12]. Construction accidents and casualties in many megaprojects are caused by the contractor's low safety cognition [13]. Moreover, the role of the stakeholders' social responsibility in many megaprojects is often vague, thus inducing negativity toward social behavior, such as violating social responsibility for personal gain, evading one's social responsibility, or exhibiting hypocritical behavior (HB) [14]. Successful implementation of MSR requires close cooperation among all parties during the entire project life cycle. However, the motivations and factors that influence the social responsibility behavior of each stakeholder vary, thus leading to different MSR behaviors (MSRBs). Their behavior exhibits remarkable multiheterogeneity, complex 
situational dependence, and dynamic evolution [14]. As the project phase advances, various factors, such as construction environment, project system, and public appeals, affect the behavior selection of social responsibility.

In-depth exploration of the underlying mechanism of stakeholders' MSRB selection is necessary to achieve effective social responsibility behavior management and ensure the synergy of the social responsibility behavior at all stages of the project life cycle. Parsons' social action theory holds that social action includes four main elements, namely, actor, behavioral purpose, condition and means, and normative orientation. Purpose is the future state of affairs expected by the subject; conditions and means clarify the situation that the subject can and cannot control, respectively; and normative orientation indicates the subject's preference of means. Based on this theory, previous studies summarize the correspondence among the elements of behavioral systems, such as MSR subjects, behavior, and situations. Key actors, such as construction units and governments, are identified, and unilateral and interactive behaviors are classified. In addition, situation is introduced to construct a MSRB selection model, which emphasizes that the stakeholders' selection of social responsibility behavior is under the combined effect of the internal characteristics of the organization, interorganizational relations, and external scenarios in megaprojects [14].

However, the effect of these aspects (i.e., internal characteristics, interorganizational relations, and external scenarios) on the actors' behavior selection in megaprojects and the degree of impact remain unclear. This study aims to empirically test the impact of relevant influencing factors on MSRB. First, HB and synergistic behavior (SB) are selected as endogenous variables. HB symbolizes the phenomenon in which the subject's behavior is exaggerated and falsified when performing social responsibility [15]. SB is characterized by the multisubject and synergistic implementation of MSR and improvement of social welfare [16]. Second, the influencing factors of the three levels (i.e., the institutional pressure (IP) and mutual feedback mechanism (MFM) at the external scenarios level, relationship quality (RQ) and external appeal (EA) at the interorganizational relationship level, and the social responsibility cognition (SRC) at the internal level of the organization) are identified as exogenous variables. The influence path model between endogenous and exogenous variables is constructed. This study explored the behavior selection mechanism of stakeholders toward MSR through survey questionnaires. Finally, the core viewpoints are summarized, and the guiding suggestions for carrying out major engineering social responsibility behaviors are given on the basis of the empirical results combined with the actual social responsibility of major projects.

\section{Theoretical Background and Research Hypothesis}

2.1. Social Responsibility Behavior in Megaprojects. MSRB means that under the combined effect of institutional environment and social pressure, the stakeholder attempts to cope with MSR issues related to the organization and the corresponding actions taken for this purpose, whether positive or negative, because of the social responsibility consciousness of the organization [14]. The stakeholders' choice of social responsibility behavior in specific projects not only depends on their own traits [17] but also on the project characteristics and other participants because different stakeholders have distinct social responsibilities in various project stages.

Research on social responsibility of construction projects is in its primary exploration stage. In the existing literature, the mechanism of social responsibility is discussed mainly around a single subject [18]. Moreover, as a contractor bears the MSR for construction, the social responsibility behavior of the contractor has become the focus of attention from all walks of life. For example, Qi et al. [19] proposed the green construction driving mechanism and action path of construction enterprises. Liu and Liang [20] started from the road construction stage to explore the cultivation path of the social responsibility behavior of the contractor. Basing on a stakeholder perspective, Liao et al. [21] identified seven stakeholders in the construction industry and constructed a social responsibility behavior framework that involves various stakeholders to guide the construction company to implement social responsibility behavior at the project level. However, MSR involves multiple stakeholders and complex project construction backgrounds. Existing social responsibility behavior analysis, situational research, and driving mechanisms from the perspective of single corporation are not fully compatible with MSR [14]. The objective laws of social responsibility behavior in the selection and evolution of major projects must be explored.

Xie et al. [14] emphasized that MSRBs include unilateral and interactive behaviors. In unilateral behavior, disguise behavior is negative based on the perspective of social responsibility performance. This behavior is similar to greenwashing, which means that the enterprise intentionally uses symbolic rather than substantive behavior [22]. In contrast with the lack of social responsibility, this behavior implies that the actors are aware and have made a commitment or propaganda but have not practiced their social responsibility [23]. Such fraudulent behavior should be avoided in megaprojects because it not only does not improve social welfare but also wastes valuable social public resources. In megaprojects, the ability of social responsibility behavior subjects cannot be limited to a large number of social responsibilities. In the face of pressure from the public media and supervision by various stakeholders, they may opt to pretend to win by word-of-mouth and establish a good image. This study defines this hypocritical social responsibility behavior as disguise, which is a false fraudulent behavior in which the subject pretends to perform social responsibility to maintain its own image or under external pressure.

In interactive behavior, $\mathrm{SB}$ is a positive social behavior that is conducive to improve social well-being. This behavior is in line with the concept of collaborative governance called for in today's megaproject construction [16]. The complexity 
of megaprojects and the variability of risks strengthen the dependence of subjects on one another and require close and deep synergy to better address social responsibility issues [24]. Ma et al. constructed a governance of MSR framework for "government-business-society" [16]. The SB has strengthened the overall awareness and cohesiveness of megaproject organizations, enhanced the ability and efficiency of response to engineering risks, and enabled social responsibility issues in megaprojects to be resolved timely and effectively. Cooperative implementation is a behavior of planning, decision-making, and implementation with other subjects in the form of communication, negotiation, and cooperation when the subject is faced with megaproject social responsibilities with multidimensional behavioral interaction and dynamic characteristics. This behavior is defined as synergistic.

In view of the importance and representativeness of both behaviors, this study selects $\mathrm{HB}$ and $\mathrm{SB}$ as the endogenous variables.

2.2. IP and MSRB. Considering the project and social attributes of megaprojects, the external context is extensive, involving many influencing factors, including constraints of macro systems (e.g., laws and regulations, contract documents) and impacts of project characteristics (e.g., major project types and construction environmental conditions) $[14,25]$. Scholars discussed the application value of institutional theory in major projects [26], and the role of institutional norms has gradually attracted the attention of scholars in the field of construction engineering. IP is an obvious external influence factor, but its influence is inconsistent due to differences in research perspectives. For example, the government punishment mechanism stimulates the environmental behavior of enterprises, but the illegal cost and profit-seeking nature of the enterprise limit the incentive effect of the regulation [27]. Nevertheless, in the field of construction engineering, Qi and other scholars found that government environmental regulations are significantly related to contractors' green construction [19].

In organization field theory, the field institution guides the behavior of the subject, limiting the scope of the action plan. Social responsibility behavior, as a kind of collective behavior in the field, should also meet the "legality" requirement of the institution $[28,29]$. The IP dimension in this study includes mandatory institution, such as construction laws, contracts, industry, and norms. These mandatory institutions have a clear reward and punishment nature. The behavior subject of social responsibility must pay attention to the terms of the contract and the requirements of social responsibility in the law. If they are violated, then the subject will be punished. Relevant empirical research demonstrates that a reasonable and clear punishment mechanism effectively controls a company's environmental compliance with regulations [27]. Ge et al. also confirmed that mandatory IP significantly promotes social responsibility behavior in megaproject environments [30].

From the perspective of rational people, the actors must weigh the cost of action to implement social responsibility and the penalty cost caused by the nonfulfillment of social responsibility. They must also pretend to perform but not to pay the cost of their corresponding action to obtain the maximum benefit. HB can win the greatest benefit at the lowest cost, but this behavior is contrary to institutional requirements. The lack of the normative nature of the institution place the behavior subject at risk, that is, the behavior subject will suffer substantial losses after the behavior is exposed. The contract and project management system in megaprojects not only constitute the reference standard for the actions of various actors but also form the relationship of interests, powers, and responsibilities among the actors. These factors are the normative basis for joint actions, such as communication, negotiation, and decision-making, when the behavior subject deals with MSR issues. In addition, contracts and regulations are often inescapable. Under the pressure of having to fulfill the responsibility and the difficulty of achieving it alone, the behavior subjects will actively seek help and support from others.

Hypothesis 1a. IP positively affects SB.

Hypothesis $1 b$. IP negatively affects HB.

2.3. MFM and MSRB. The MFM, which includes information disclosure and communication mechanism, is the key system to improve project transparency, ensure the collaborative analysis of subjects, and make decisions on MSR issues [31]. Communication is an important means for the construction project team to know and cooperate with one another. A good communication mechanism provides a way for the actor to communicate; standardizes the communication process, methods, and requirements; and helps eliminate understanding bias and avoid information silos. Previous research on organizational transparency confirms that transparency plays a positive role in increasing members' trust in the organization [32], and this trust lays the foundation for MSR actors to coordinate social responsibility. Wang [31] emphasized that the information sharing mechanism directly affects the evolution of stakeholders to cope with the social responsibility crisis in major engineering projects. Information technology and strategy have created possibilities for collaboratively solving social responsibility crisis. Ma et al. [16] believed that transparency plays a role in MSR governance, such as preventing and combating corruption and power abuse. An effective MFM helps subjects pay attention to the interests of stakeholders, thereby gaining the support and collaboration of megaproject teams and reducing the loss of social responsibility crisis. By contrast, in the study of hypocritical social responsibility behavior, the reasons for that are also closely related to exposure difficulties. However, in the case of effective information disclosure system, the hidden behavior of the subject is exposed, and the participating parties realize that the information of the social responsibility behavior of the party will be disclosed. Under such psychological pressure, the actor reduces speculative behavior with a lucky attitude. Frequent communication also increases the exposure of the social responsibility behavior of the subject, thereby causing difficulty in concealing and falsely performing social responsibility and raising the 
possibility that inconsistent words and deeds are perceived by the subject.

Hypothesis 2a. MFM positively affects SB.

Hypothesis 2b. MFM negatively affects HB.

2.4. RQ and MSRB. Stakeholders always affect the decisionmaking of the actors [21], and the actors must consider the interests and attitudes of stakeholders during behavior selection. Therefore, the relationship of organizations affects the selection of actors' social responsibility behavior [14]. Interorganizational relationships can be divided into two types: participating and nonparticipating parties in construction. This study opts to use RQ as a variable to measure the interaction among participants to determine the influence of the relationship between the participants. RQ is related to the project performance and satisfaction of the participants, such as the owner [33]. A harmonious working atmosphere is conducive to synergy and other social responsibility interactions.

$\mathrm{RQ}$ is a variable that measures the degree of interaction among various subjects in a project. RQ includes commitment [34], communication, coordination, trust [35], and fairness [36]. Black et al. [37] used trust, confidence, and communication to investigate the relationships in engineering projects. The subdimensions of these relationships are closely related to interaction behavior. Communication and commitment shape the impression of the actor on the other side of the project. Trust allows the behavior subject to have the willingness to contact and cooperate. Therefore, good RQ is achieved when many parties are willing to coordinate social responsibility and reduce the occurrence of negative behavior, such as hypocrisy. Scholars, including Lu and Wang [38] and $\mathrm{Wu}$ et al. [39], found that the relationship between RQ and engineering project cooperation and coordination behavior is significantly correlated. SB also emphasizes that multiparty subjects rely on collective power to fulfill social responsibilities on the basis of trust and communication. RQ determines the frequency and implementation effect of collaborative behavior.

Hypothesis 3a. RQ positively affects SB.

\section{Hypothesis $3 b$. RQ negatively affects $\mathrm{HB}$.}

As a variable for the participants to perceive and evaluate each other's interaction behavior, RQ includes subelements such as trust, commitment, communication, cooperation, and reciprocity. Trust and fulfillment of commitments are prerequisites for establishing cooperative relationships. Communication promotes information transmission, so that all parties can resolve disputes through joint efforts, achieve reasonable and fair benefits, and form a win-win situation. The subdimension of RQ indicates that the communication and information feedback between the parties can enhance RQ [24]; efficient communication and transparent information disclosure mechanisms in megaprojects have laid a solid foundation for the mutual exchange of participants. Efficient information communication strengthens the mutual understanding between the parties and is conducive to the formation of good partnerships. Moreover, the quality of communication is an evaluation criterion for RQ. Therefore, RQ can be regarded as a mediator variable, which plays a mediating role in the impact of MFM on MSRB.

Hypothesis 3c. MFM indirectly affects MSRB through RQ.

2.5. EAs and MSRB. EAs for MSR resulted from nonparticipating parties $[3,16]$. Among the influences of nonparticipating parties, many scholars investigated social responsibility and proposed that social pressures, such as government regulation and public participation, remarkably affect social responsibility behavior [19]. With the aforementioned conclusions from the existing literature as basis, this study uses EAs as research variables and selects nonparticipating parties, including public media, local community residents, government regulatory agencies, and NGOs, for discussion. The requirements and supervision of such organizations for megaprojects reflect the social expectations of major social responsibility behavior from outside the project.

Projects carry considerable social responsibility expectations when the public and local communities are highly concerned about them, and the negative effects of failing to fulfill social responsibilities are high [4]. At the same time, government regulators and NGOs have constrained the social responsibility of the participants [19, 30]. Judging from the characteristics of megaprojects, large investment and long construction period greatly affect the social economy and ecology. The social attributes of major projects have been repeatedly emphasized in academic circles and engineering practice $[11,16,40]$. In this context, MSRB subjects have to pay attention to the demands of major social projects and prevent social conflicts. The demand for social responsibility in the outside world is related to the project as a whole, requiring the government to perform the top-level command and construction unit to coordinate the implementation of multiple designers, contractors, and supervisors to maximize social satisfaction [41]. However, excessive EAs correspond to high manpower and resource investment, and the increase in the cost of social responsibility behavior make the subjects inclined to pretend to fulfill their social responsibility for maintaining a good image $[42,43]$. That is, EAs lead to the emergence of false social responsibility behavior.

Hypothesis 4a. External claims positively affect SB.

Hypothesis $4 b$. External claims negatively affect HB.

2.6. SRC and MSRB. The earliest theory of action and the farreaching theory of rational behavior demonstrate a direct relationship between cognition and behavior $[44,45]$. Scholars who study CSR empirically showed that SRC is positively correlated with social responsibility behavior [46, 47]. 
Managers' cognitive attitudes toward social responsibility directly affect organizational behavioral decision-making [46]. Research confirms that managers' perceptions of social responsibility directly affect organizational social responsibility behavior or indirectly influence the social responsibility behaviors of actors. In megaprojects, the subjects' understanding of the social responsibility of megaprojects determines their attitude toward social responsibility behavior, which in turn affects actual behavior selection.

In the current situation, the management personnel in the participating organizations remain vague about the concept of MSR, thus requiring increased attention to the three traditional construction goals and ignoring social expectations. However, failure to properly consider social responsibility issues may not be due to negative values of engineering managers but because of their insufficient understanding of the major engineering social responsibilities. From a social person perspective, the profound and clear understanding of the actor toward social responsibility of megaprojects indicates that he is inclined to select positive social responsibility behavior, such as synergy, while reducing negative social responsibility behavior, such as hypocrisy against values.

Hypothesis $5 a$. SRC positively affects SB.

Hypothesis $5 b$. SRC negatively affects HB.

Figure 1 depicts the conceptual model of this study based on the hypotheses.

\section{Methodology}

3.1. Measurement. Combining the identified influencing factors, the exogenous variables investigated in this study include five potential variables according to the classification of variables in the structural equation model. These variables are IP, MFM, RQ, EA, and SRC. Endogenous variables include two potential variables, namely, camouflage and cooperative behavior. The scale uses a 7-point Likert scale that ranges from 1 (strongly disagree) to 7 (strongly agree) to ensure measurement accuracy. The scale items draw on existing research, and on this basis, the situation of major projects is combined to modify the design. Table 1 lists the variable measurement items and reference sources (" $R$ " means reverse item).

3.2. Sample and Data Collection. Considering that the managers of the participating organizations in megaprojects have a clear understanding of the implementation of megaproject social responsibilities, the questionnaire was distributed to the management staff of the participating parties. Before the formal investigation, a preset questionnaire survey was conducted on 32 on-the-job masters of engineering management to test the validity of the questionnaire. According to the respondent's answer and feedback, combined with the research group's discussion results, the structure and expression of the item were modified to form a formally issued questionnaire.
After revising the questionnaire according to the trial situation, 195 questionnaires were distributed to the management personnel of the participating parties who had remarkable engineering experience in the form of online publication and mailing, and 145 were recovered, with a recovery rate of $74.4 \%$. A total of 127 valid questionnaires were screened on the basis of the time of answering the questionnaire, the years of participating in megaproject, and whether the answer was neutral, with an effective rate of $87.6 \%$. The following megaprojects were selected from the questionnaire: the main bridge and Zhuhai port of Hong Kong-ZhuhaiMacao Bridge and the infrastructure project of Nanning East Railway Station in Guangxi Province, Zhuhai Hengqin New Area Project of Guangdong Pilot Free Trade Zone, Shanghai World Expo Project, and Shenzhen Qianhai City New Center Construction Project. The sample source covers developed areas in southern China and has certain representativeness.

Table 2 provides the descriptive statistics of the respondents. The respondents were mainly the owner and the government $(43.3 \%)$, followed by the contractor $(22.8 \%)$. Differences are observed in the megaproject social responsibilities of various participating parties. In contrast with other units, such as survey and design, the MSR issues faced by owners, governments, and contractors are becoming complicated. This study used one-way analysis of variance (ANOVA) to test the two variables of $\mathrm{HB}$ and $\mathrm{SB}$ among different participating organizations to test the problem considering that differences in the choice of social responsibility behaviors for project roles may be observed [47]. The results indicate no significant difference ( $P$ value is 0.203 and 0.571 , both values are greater than 0.05 ).

3.3. Selection of Research Tools. The reliability of the latent variable scale in the context of MSR needs to be tested because the development stage of the scale is based on the measurement scale of existing measurement-related research. This study used exploratory and confirmatory factor analysis methods to correct and detect the scale. An empirical study was conducted using the PLS-SEM method in the hypothesis testing phase. In the structural equation model test, the study tested the results of AMOS and SmartPLS software, and PLSSEM was used as the data analysis tool according to the conclusions of existing research. PLS-SEM is suitable for early exploratory research $[24,47]$. The potential variables of this study, such as IP, MFM, and cooperative behavior, are newly proposed. The impact path is an extension of existing research results or theoretical frameworks, but, overall, it is still in the preliminary exploration stage. PLS-SEM is also suitable for studies with small sample [55]. AMOS, LISREL, and Mplus are the mainstream software for today's structural equation model research. The sample size must be larger than the sample size, and the boundary should be 200. The number of samples in this study (127) was applied by PLS-SEM.

\section{Data Analysis}

4.1. Factor Analysis. Exploratory factor analysis was first performed to test the validity of the MSRB measurement 


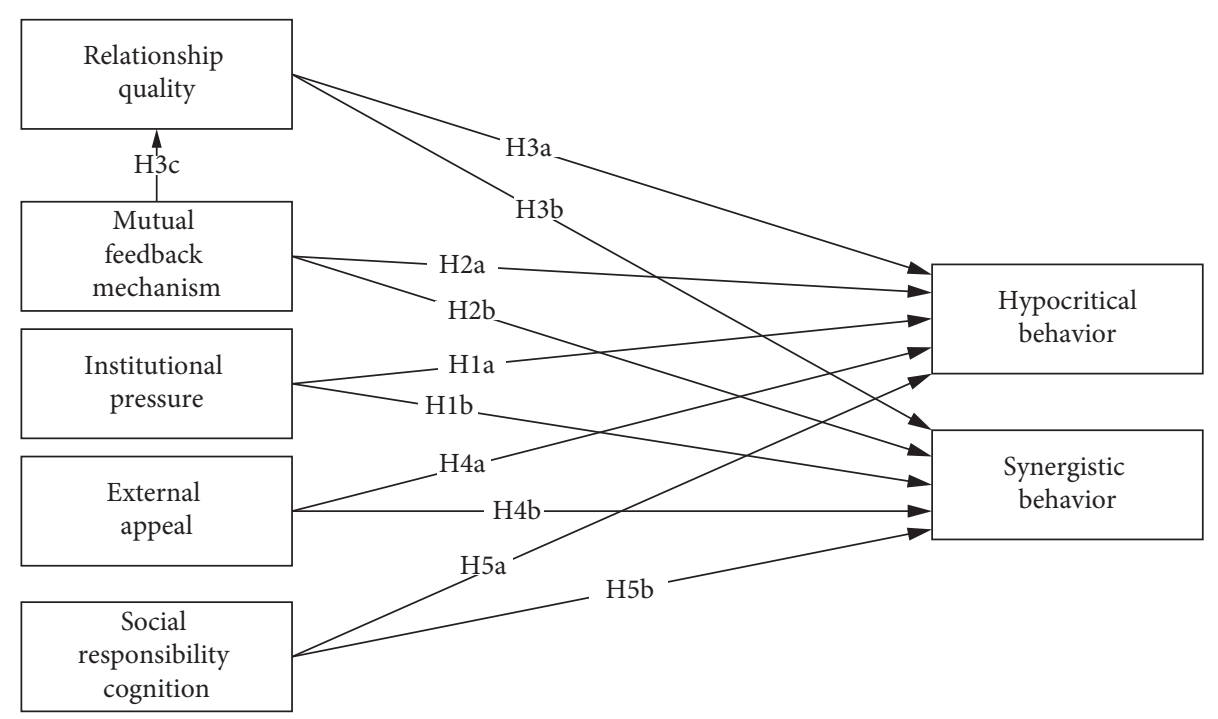

FIgURE 1: MSRB selection concept model.

TABle 1: Development and design of the scale items.

\begin{tabular}{|c|c|c|}
\hline Construct & Items & Reference source \\
\hline Institutional pressure & $\begin{array}{c}\text { PRES2: contract documents contain clear } \\
\text { requirements for project quality and safety, handling } \\
\text { public social events, and ecological environmental } \\
\text { protection } \\
\text { PRES3: contents of construction standard } \\
\text { specification regarding quality and safety of } \\
\text { megaprojects, environmental protection, } \\
\text { occupational health, green construction, etc. are } \\
\text { specific } \\
\text { PRES4: project culture advocates the importance of } \\
\text { engineering quality and safety, social impact, and } \\
\text { ecological environmental protection } \\
\text { PRES5: project has strict supervision and information } \\
\text { feedback on engineering quality and safety, } \\
\text { occupational health, social impact, and ecological } \\
\text { environment }\end{array}$ & Wang et al. [30]; Zheng [48] \\
\hline Mutual feedback mechanism & $\begin{array}{l}\text { MFM1: project has adopted effective communication } \\
\text { methods such as charts, tables, etc. } \\
\text { MFM2: through regular meetings, information } \\
\text { sharing between project parties is very accurate } \\
\text { MFM3: it is very timely to communicate with other } \\
\text { participants through documents } \\
\text { MFM4: project team hopes that the participants know } \\
\text { what the project is doing and why }\end{array}$ & Wu et al. [39]; Holland et al. [32] \\
\hline Relationship quality & $\begin{array}{l}\text { REQUA1: other project participants always abide by } \\
\text { our commitment to us } \\
\text { REQUA2: we can trust that the project participants } \\
\text { are sincere } \\
\text { REQUA3: when making important decisions, the } \\
\text { project participants will consider our interests. } \\
\text { REQUA5: we are satisfied with the project } \\
\text { participants in terms of technology and management. } \\
\text { REQUA6: considering the overall performance of the } \\
\text { project participants, it can be said that they have } \\
\text { reached our expectations }\end{array}$ & Lu and Wang [38]; Xu et al. [49] \\
\hline
\end{tabular}


TABle 1: Continued.

\begin{tabular}{|c|c|c|}
\hline Construct & Items & Reference source \\
\hline External appeal & $\begin{array}{c}\text { EXAPPE2: relevant government regulatory } \\
\text { authorities require attention to social responsibility } \\
\text { issues } \\
\text { EXAPPE3: the public is highly concerned about } \\
\text { megaprojects, and the media frequently reports on } \\
\text { project social responsibility. } \\
\text { EXAPPE5: relevant NGOs require projects to pay } \\
\text { attention to social responsibility issues }\end{array}$ & Wang et al. [30]; Zhao [50] \\
\hline Social responsibility cognition & $\begin{array}{l}\text { SCAW3R: the society's expectation for megaprojects } \\
\text { is only to complete the construction task (R) } \\
\text { SCAW4R: we must pay attention to the construction } \\
\text { of megaprojects and should not assume social } \\
\text { responsibility }(R) \text {. } \\
\text { SCAW5R: taking social responsibility consumes our } \\
\text { extra resources and deviates from the main project } \\
\text { objectives (R) }\end{array}$ & $\mathrm{Xu}$ and Liang [51]; Zheng [48] \\
\hline Hypocritical behavior & $\begin{array}{l}\text { HYBE1R: when we fulfill our social responsibilities, } \\
\text { we can fully do what we say and do (R) } \\
\text { HYBE2R: we never make an empty social } \\
\text { responsibility commitment }{ }^{\circledR} \\
\text { HYBE3R: we will not pretend to perform social } \\
\text { responsibility at any time (R) }\end{array}$ & Wagner et al. [52]; Xiao et al. [53] \\
\hline Synergistic behavior & $\begin{array}{l}\text { SYBE1: other participants can provide support to } \\
\text { help us solve social responsibility problems } \\
\text { SYBE2: we can provide support to help other } \\
\text { participants solve social responsibility issues. } \\
\text { SYBE3: when there is a social responsibility problem } \\
\text { in the implementation of the project, there is no } \\
\text { shirking responsibility. } \\
\text { SYBE4: participants actively and continuously } \\
\text { consider social responsibility issues. } \\
\text { SYBE6: in the implementation of social responsibility } \\
\text { behavior, the participants have maintained a good } \\
\text { cooperative relationship }\end{array}$ & Yan et al. [54] \\
\hline
\end{tabular}

TABle 2: Descriptive statistics of respondents.

\begin{tabular}{|c|c|c|c|}
\hline Item & Category & Number & $(\%)$ \\
\hline \multirow{4}{*}{ Organizational nature } & Government, construction unit & 55 & 43.30 \\
\hline & Survey and design unit & 24 & 18.90 \\
\hline & Contractor & 29 & 22.80 \\
\hline & Supervision, consulting, operating units, etc. & 19 & 15.00 \\
\hline \multirow{4}{*}{ Working years in engineering } & Less than 5 years & 38 & 29.90 \\
\hline & $6-10$ years & 41 & 32.30 \\
\hline & $11-20$ years & 32 & 25.20 \\
\hline & More than 20 years & 16 & 12.60 \\
\hline \multirow{3}{*}{ Working years in megaproject } & Less than 5 years & 68 & 53.50 \\
\hline & $6-10$ years & 37 & 29.10 \\
\hline & More than 10 years & 22 & 17.30 \\
\hline \multirow{7}{*}{ Project type } & Skyscraper & 35 & 27.60 \\
\hline & Large-scale event exhibition facilities & 19 & 15.00 \\
\hline & Energy base, power station, airport & 8 & 6.30 \\
\hline & High-speed rail, highway, etc. & 25 & 19.70 \\
\hline & Long bridge, mountain tunnel & 13 & 10.20 \\
\hline & Port engineering, airport & 10 & 7.90 \\
\hline & Subway & 17 & 13.40 \\
\hline
\end{tabular}


scale item, which was evaluated by KMO value and Bartlett spherical detection. Empirically, when the KMO value is higher than 0.6 and the Bartlett test reaches a significant level $(P<0.001)$, the measurement items have strong correlation and are suitable for factor analysis. In the exploratory factor analysis, the items with low factor load or cross-load condition in the measurement item were deleted. After factor analysis of measured items, five factor dimensions were extracted, which correspond to five endogenous latent variables: IP, MFM, RQ, EA, and SRC. Table 3 shows that the factor loading of the measurement items generally exceeds 0.7 (above the limit of 0.5 ). In the same way, two factors were extracted from the endogenous variables, corresponding to $\mathrm{SB}$ and $\mathrm{HB}$. The KMO value and the Bartlett test significance of the two exploratory factor analyses met the requirements.

4.2. Scale Validity Analysis. The structural validity analysis show discriminant and aggregation validity, which are tested by SmartPLS 3.0. Table 4 lists the results of the discriminant validity test. The factor load of each item in the construct of the influencing factors and MSRB is significantly higher than the load value of other constructs. Furthermore, the minimum value of the AVE square root value of each construct is 0.862 , which is higher than the maximum correlation coefficient of other constructs by 0.832 , indicating that the scale has satisfactory discriminant validity.

Table 5 lists the results of the polymerization validity test, which is evaluated by Cronbach's $\alpha$ value, mean variation extract (AVE) value, and combination reliability (CR). Empirically, a CR of 0.7 or more is considered relatively stable, and the AVE criterion is 0.50 . When it is greater than this value, the latent variable has an ideal polymerization validity [51]. The Cronbach's $\alpha$ value of each potential variable obtained before is above 0.85 , which is greater than 0.7 , followed by the CR value of the latent variable, which is almost above 0.9 , and the AVE value is approximately 0.80 , and both are above 0.74 . The three indicators show that the scale has satisfactory structural validity. In summary, the measurement items represent the measurement of the influencing factors and MSRB.

4.3. PLS-SEM Analysis. The hypothesis test of the previous behavior selection was carried out by using SmartPLS 3.0 software. According to the theoretical hypothesis, the influence paths of the five influencing factors on the endogenous variables of the two behavioral modes were drawn. After the questionnaire data were imported, the model was run, and the results are illustrated in Figure 2. As an influential factor, the R-party interpretation level of $\mathrm{HB}$ and $\mathrm{SB}$ reached 0.510 and 0.723 , indicating that the model explained the two behaviors to a high degree, respectively. The path coefficient of the relationship between the MFM and the RQ is 0.592 , and the $P$ value is $<0.001$, indicating that the impact is very significant. In addition, the R-square value is 0.351 , indicating that the MFM has a high degree of interpretation of the RQ. The path hypothesis of the influence of RQ on $\mathrm{HB}$ and SB is supported and reached the level of $P<0.001$. The direct influence of MFM on SB is insignificant $(P>0.05)$. Thus, feed mechanism indirectly affects $\mathrm{HB}$ and SB through $\mathrm{RQ}$. The influence of IP and EA on HB passed the hypothesis test at the significance level of 0.05 . The influence path of SRC variables on the two social responsibility behavior did not reach the significant level $(P$ value $>0.05)$. Table 6 summarizes the results of the hypothesis test.

\section{Discussion and Implication}

As an exploratory study, this paper attempts to use social action theory, through social responsibility cognition at the level of internal characteristics, relationship quality and external appeals at the level of interorganizational relations, and mutual feedback mechanism and institutional pressure at the level of external scenarios to explore the decisionmaking of stakeholders on hypocritical behavior and synergistic behavior in megaproject social responsibility. The empirical results show that the theoretical framework of megaproject social responsibility behavior choice proposed by previous research has certain explanatory power for the behavior selection of participating parties. In addition, there may be differences in the influencing factors and influence paths of different behaviors. Specifically, for the hypocritical behavior and synergistic behavior in this study, the relationship quality has a direct impact on both behaviors, which means that relationship quality not only effectively promotes the cooperation and mutual assistance of the participants in the implementation of social responsibility, but also plays an effective role in reducing disguised social responsibility behavior. The mutual feedback mechanism indirectly affects these two behaviors selection through the relationship quality as mediator variable. For hypocritical behaviors, in addition to the influence path of the above variables, institutional pressure and external appeals can directly effectively inhibit the false social responsibility behavior of the participating parties. However, for the synergistic behavior, among the variables selected in this paper, except for the mutual feedback mechanism and the relationship quality, the residual exogenous variables are not statistically significant. In addition, it is surprising that the impact of social responsibility cognition on both behaviors is not significant. This means that the level of social responsibility is not effective in reducing the performance of the participating parties in making false social responsibility and promoting the assistance for other participants in fulfilling their social responsibilities.

5.1. Influential Path of IP. The institution in this study is the regulatory requirement for MSR in industry norms, contract terms, and project culture. According to the empirical results of two statistical methods, IP has an inhibitory effect on HB but does not significantly affect SB. The results confirm that IP affects the choice of social responsibility behavior of the subjects in megaprojects. However, the degree of impact is not very high and only passes the significant level of 0.05 , indicating that simply pursuing institutional constraints to promote the fulfillment of megaproject social responsibilities 
TABLE 3: Exploratory factor analysis of endogenous variables.

\begin{tabular}{|c|c|c|c|c|c|}
\hline Item & Ingredient1 & Ingredient2 & Ingredient3 & Ingredient 4 & Ingredient5 \\
\hline IP2 & 0.816 & 0.315 & 0.105 & 0.069 & 0.056 \\
\hline IP3 & 0.832 & 0.226 & 0.096 & 0.131 & 0.082 \\
\hline IP4 & 0.695 & 0.381 & -0.006 & 0.305 & -0.006 \\
\hline IP5 & 0.706 & 0.236 & 0.311 & 0.167 & 0.143 \\
\hline MFM1 & 0.287 & 0.732 & -0.048 & 0.241 & 0.09 \\
\hline MFM2 & 0.206 & 0.845 & 0.113 & 0.197 & 0.149 \\
\hline MFM3 & 0.301 & 0.799 & 0.286 & 0.082 & 0.136 \\
\hline MFM4 & 0.294 & 0.78 & 0.042 & 0.053 & 0.165 \\
\hline RQ1 & 0.263 & -0.058 & 0.838 & 0.044 & -0.172 \\
\hline RQ2 & 0.267 & 0.006 & 0.858 & 0.203 & -0.094 \\
\hline RQ3 & -0.011 & 0.13 & 0.861 & 0.189 & -0.151 \\
\hline RQ5 & 0.043 & 0.119 & 0.881 & 0.139 & 0.035 \\
\hline RQ6 & -0.012 & 0.122 & 0.816 & 0.204 & -0.069 \\
\hline EA2 & 0.324 & 0.3 & 0.254 & 0.675 & 0.067 \\
\hline EA3 & 0.096 & 0.216 & 0.277 & 0.839 & 0.098 \\
\hline EA5 & 0.29 & 0.072 & 0.413 & 0.651 & 0.094 \\
\hline SCA3R & -0.005 & 0.371 & -0.105 & -0.294 & 0.695 \\
\hline SCA4R & 0.055 & 0.134 & -0.205 & 0.165 & 0.864 \\
\hline SCA5R & 0.16 & 0.063 & -0.056 & 0.203 & 0.879 \\
\hline Factor extraction & $\begin{array}{c}\text { Institutional } \\
\text { pressure }\end{array}$ & $\begin{array}{c}\text { Mutual } \\
\text { feedback } \\
\text { mechanism }\end{array}$ & $\begin{array}{c}\text { Relationship } \\
\text { quality }\end{array}$ & $\begin{array}{c}\text { External } \\
\text { appeal }\end{array}$ & $\begin{array}{c}\text { Social } \\
\text { responsibility } \\
\text { cognition }\end{array}$ \\
\hline Variance interpretation ratio (\%) & 22.128 & 16.836 & 15.856 & 11.565 & 11.191 \\
\hline Cumulative variance interpretation ratio (\%) & 77.576 & & & & \\
\hline
\end{tabular}

TABLE 4: Discriminant validity analysis of measurement scale.

\begin{tabular}{|c|c|c|c|c|c|c|c|}
\hline Constructive & $\begin{array}{c}\text { Mutual feedback } \\
\text { mechanism }\end{array}$ & $\begin{array}{c}\text { Hypocritical } \\
\text { behavior }\end{array}$ & $\begin{array}{c}\text { Relationship } \\
\text { quality }\end{array}$ & $\begin{array}{c}\text { Institutional } \\
\text { pressure }\end{array}$ & $\begin{array}{c}\text { Synergistic } \\
\text { behavior }\end{array}$ & $\begin{array}{c}\text { External } \\
\text { appeal }\end{array}$ & $\begin{array}{c}\text { Social responsibility } \\
\text { cognition }\end{array}$ \\
\hline $\begin{array}{l}\text { Mutual feedback } \\
\text { mechanism }\end{array}$ & 0.907 & & & & & & \\
\hline $\begin{array}{l}\text { Hypocritical } \\
\text { behavior }\end{array}$ & -0.492 & 0.895 & & & & & \\
\hline Relationship quality & 0.59 & -0.659 & 0.914 & & & & \\
\hline $\begin{array}{l}\text { Institutional } \\
\text { pressure }\end{array}$ & 0.774 & -0.574 & 0.591 & 0.901 & & & \\
\hline Synergistic behavior & 0.576 & -0.79 & 0.832 & 0.616 & 0.89 & & \\
\hline External appeal & 0.7 & -0.624 & 0.688 & 0.724 & 0.685 & 0.913 & \\
\hline $\begin{array}{l}\text { Social responsibility } \\
\text { cognition }\end{array}$ & -0.001 & 0.122 & -0.264 & -0.068 & -0.218 & -0.157 & 0.862 \\
\hline
\end{tabular}

Note: The bold is the square root of the potential variable AVE value. Here, in order to compare with the correlation coefficient matrix, the original autocorrelation coefficient (1.000) is replaced.

is insufficient. For example, the Hong Kong-Zhuhai-Macao Bridge under the common constraints of different construction institution of Guangdong, Hong Kong and Macao, while participating in the construction standards according to different systems, the participating parties also need to resolve the differences between the system norms to solve the lack of social responsibility.

Although the effectiveness of the system is not the most effective, it cannot be ignored. The empirical analysis of Wang Ge and other scholars emphasized that the imitation and normative pressures under institutional theory are more effective than those in mandatory institutions [30]. Therefore, the selection of "standards engineering" to create a typical model of social responsibility behavior, give play to the influence of experts and scholars, speed up the formulation of megaproject social responsibility industry norms and assessment mechanisms, and create a good learning atmosphere for social responsibility practices and other practices will greatly benefit the entire society and megaprojects. In addition, the application of institutional theory in megaproject, which has a positive effect on social stability and regulation of megaproject construction behavior, should be continuously explored by scholars [26].

5.2. Influence Path of MFM and RQ. According to the empirical results, the MFM is based on the RQ variable, which indirectly affects the MSRB selection. As a technology platform and management model to strengthen trust, communication, and collaboration among participants, MFM has remarkable effects on megaproject organization integration, information sharing, and decision-making negotiation [31], which are 
Table 5: Analysis of the polymerization validity of the measurement scale.

\begin{tabular}{|c|c|c|c|c|c|c|c|}
\hline Latent variable & Measurement item & Factor load & Measurement error variance & $P$ value & Cronbach's $\alpha$ & AVE & $\mathrm{CR}$ \\
\hline \multirow{4}{*}{ Institutional pressure } & PRES2 & 0.918 & 0.157 & $* * *$ & \multirow{4}{*}{0.923} & \multirow{4}{*}{0.813} & \multirow{4}{*}{0.945} \\
\hline & PRES3 & 0.917 & 0.159 & $* * *$ & & & \\
\hline & PRES4 & 0.882 & 0.222 & $* * *$ & & & \\
\hline & PRES5 & 0.888 & 0.211 & $* * *$ & & & \\
\hline \multirow{4}{*}{ Mutual feedback mechanism } & MFM1 & 0.9 & 0.19 & $* * *$ & \multirow{4}{*}{0.928} & \multirow{4}{*}{0.822} & \multirow{4}{*}{0.949} \\
\hline & MFM2 & 0.918 & 0.157 & $* * *$ & & & \\
\hline & MFM3 & 0.931 & 0.133 & $* * *$ & & & \\
\hline & MFM4 & 0.876 & 0.232 & *** & & & \\
\hline \multirow{5}{*}{ Relationship quality } & REQUA1 & 0.91 & 0.171 & $* * *$ & \multirow{5}{*}{0.951} & \multirow{5}{*}{0.836} & \multirow{5}{*}{0.962} \\
\hline & REQUA2 & 0.938 & 0.12 & $* * *$ & & & \\
\hline & REQUA3 & 0.923 & 0.149 & $* * *$ & & & \\
\hline & REQUA5 & 0.914 & 0.165 & $* * *$ & & & \\
\hline & REQUA6 & 0.887 & 0.214 & $* * *$ & & & \\
\hline \multirow{3}{*}{ External appeal } & EXAPPE2 & 0.914 & 0.164 & $* * *$ & \multirow{3}{*}{0.9} & \multirow{3}{*}{0.833} & \multirow{3}{*}{0.937} \\
\hline & EXAPPE3 & 0.921 & 0.152 & $* * *$ & & & \\
\hline & EXAPPE5 & 0.903 & 0.185 & $* * *$ & & & \\
\hline \multirow{3}{*}{ Social responsibility cognition } & SCAW3R & 0.931 & 0.133 & 0.001 & \multirow{3}{*}{0.865} & \multirow{3}{*}{0.743} & \multirow{3}{*}{0.895} \\
\hline & SCAW4R & 0.904 & 0.183 & $* * *$ & & & \\
\hline & SCAW5R & 0.738 & 0.456 & 0.002 & & & \\
\hline \multirow{3}{*}{ Hypocritical behavior } & HYBE1R & 0.862 & 0.257 & $* * *$ & \multirow{3}{*}{0.876} & \multirow{3}{*}{0.801} & \multirow{3}{*}{0.924} \\
\hline & HYBE2R & 0.905 & 0.182 & $* * *$ & & & \\
\hline & HYBE3R & 0.918 & 0.157 & *** & & & \\
\hline \multirow{5}{*}{ Synergistic behavior } & SYBE1 & 0.863 & 0.255 & $* * *$ & \multirow{5}{*}{0.934} & \multirow{5}{*}{0.792} & \multirow{5}{*}{0.95} \\
\hline & SYBE2 & 0.907 & 0.177 & $* * *$ & & & \\
\hline & SYBE3 & 0.88 & 0.225 & $* * *$ & & & \\
\hline & SYBE4 & 0.914 & 0.165 & $* * *$ & & & \\
\hline & SYBE6 & 0.883 & 0.22 & $* * *$ & & & \\
\hline
\end{tabular}

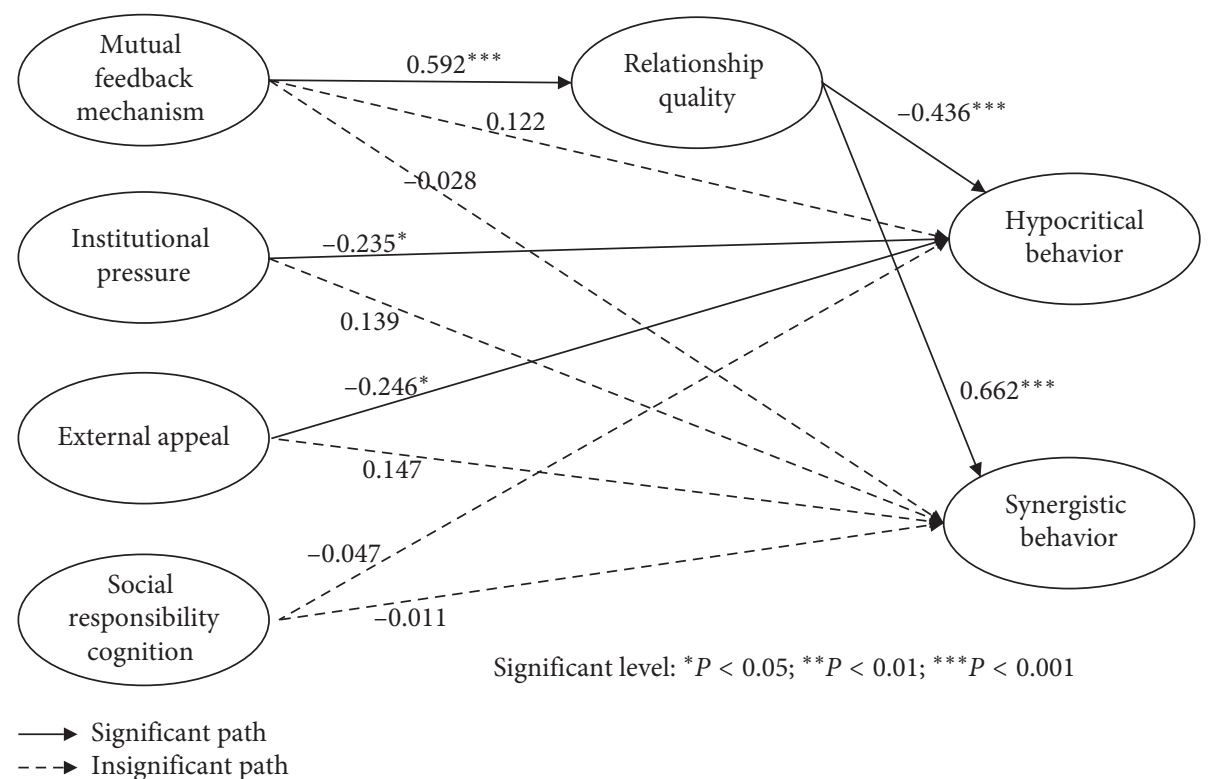

FIGURE 2: PLS-SEM analysis results.

beneficial in improving the relationship performance between subjects [24] and RQ. In the analysis results of this study, the path coefficient of the relationship between the MFM is high (0.592), and the significance level ( $P$ value) is below 0.001 . MFM plays a key role in the interaction behavior of megaprojects. The impact of the path indicates that the RQ has great impetus in the MSRB. The impact path assumed in this study is the RQ composed of elements, such as trust and communication, which help enhance the SB in MSR. On a recently research of Zheng [48], the relationship behavior in megaproject construction greatly contributes to the improvement of RQ [24]. Although the starting point of study is 
TABLe 6: Hypothesis test results.

\begin{tabular}{lcccc}
\hline & Path coefficient & $T$ value & $P$ value & Test result \\
\hline $\mathrm{MFM} \longrightarrow \mathrm{RQ}$ & 0.592 & 5.793 & $<0.001$ & Accept \\
$\mathrm{MFM} \longrightarrow \mathrm{HB}$ & 0.122 & 0.862 & 0.389 & Not accepted \\
$\mathrm{RQ} \longrightarrow \mathrm{HB}$ & -0.436 & 3.990 & $<0.001$ & Accept \\
$\mathrm{IP} \longrightarrow \mathrm{HB}$ & -0.235 & 2.127 & 0.034 & Accept \\
$\mathrm{EA} \longrightarrow \mathrm{HB}$ & -0.246 & 2.081 & 0.038 & Accept \\
$\mathrm{SRC} \longrightarrow \mathrm{HB}$ & -0.047 & 0.446 & 0.656 & Not accepted \\
$\mathrm{MFM} \longrightarrow \mathrm{SB}$ & -0.028 & 0.287 & 0.774 & Not accepted \\
$\mathrm{RQ} \longrightarrow \mathrm{SB}$ & 0.662 & 8.063 & $<0.001$ & Accept \\
$\mathrm{IP} \longrightarrow \mathrm{SB}$ & 0.139 & 1.415 & 0.158 & Not accepted \\
$\mathrm{EA} \longrightarrow \mathrm{SB}$ & 0.147 & 1.461 & 0.145 & Not accepted \\
$\mathrm{SRC} \longrightarrow \mathrm{SB}$ & -0.011 & 0.225 & 0.822 & Not accepted \\
\hline
\end{tabular}

different, the consensus is that information sharing and open communication significantly affect the achievement of a highlevel RQ.

The complexity of megaprojects, whose social responsibility involves multiple subjects, requires participants work together to maximize the benefits of the project to fulfill social responsibility at the lowest cost and eliminate the risk of crisis caused by lack of social responsibility in real rather than in falsehood. Therefore, timely and accurate information services in today's major projects and the resource integration of participating parties to coordinate and effectively deal with social responsibility issues, BIM technology, cloud computing, and grid technology can create a megaproject construction atmosphere with open communication and information sharing [31]; especially for project group with hundreds of participating parties, such as Shenzhen Qianhai City New Center Construction Project or Zhuhai Hengqin New Area Project of Guangdong Pilot Free Trade Zone, these information communication technologies have a positive effect on synergistically improving project quality, progress, reducing risk and other social responsibilities, and reducing negative hypocritical performance.

5.3. Influence Path of EA. According to the empirical results, the assumption of the influence of EA on $\mathrm{HB}$ is accepted, but the impact on the cooperative behavior is not remarkable. EAs come from government regulators, the general public, the media, and relevant NGOs. The results show that the pressure of these supervisory forces on the behavior subjects of megaproject is obvious, and their demands require substantial social responsibility actions and effects, which will reduce the intentional tendency of the actors to take pretense. The act of exposure after false performance results in considerable negative effects to megaprojects.

However, for the influence of EA on camouflage behavior, Zhao et al. [50] held different views and believed that this external pressure violated the organization's interests. Thus, the organization is likely to take false actions. However, this study believes that EAs positively affect the $\mathrm{HB}$ of megaprojects. The main reason is that megaprojects are highly concerned and are key projects at the national and regional levels, such as high-speed rail and nuclear power plants. Construction units and other participants have been pressured by the public and the community at the beginning. Thus, when the appeal is strong, the risk of hypocrisy is great, and hypocrisy will be rejected by the behavior subject. The government, as the most powerful force in EA, should enhance its regulatory capabilities and increase information disclosure on megaprojects [16] to guide the improvement of megaproject.

5.4. Influence Path of SRC. During hypothesis testing, the SRC variable has no significant impact on the $\mathrm{HB}$ and SB. However, this finding does not mean that SRC has nothing to do with MSRB. However, the influence of other factors in $\mathrm{HB}$ and SB is dominant, and the SRC affects the performance of major engineering social responsibility behavior [47], and perhaps the impact of SRC on the purpose and lofty behavior is evident $[57,58]$. In the field research and interviews with project leaders and experts, although the current MSR is still a concept of academia, practitioners in the construction engineering community do not have a clear and accurate understanding of it. Nevertheless, almost everyone agrees that the responsibility of megaprojects is far more than the three major construction goals. The impact of megaprojects, like the South-to-North Water Transfer, the Three Gorges Dam and other livelihood projects, on society, economy, politics, and ecology has been deeply rooted in the hearts of the people.

\section{Limits and Prospect}

This article has limits in four areas.

First, this study attempts to demonstrate the MSRB mechanism from a systematic and global perspective. However, in the identification of influencing factors, the influencing factors with frequent occurrences and are closely related to MSRB in literature retrieval are selected. The role of the project's transparency and other factors that are not involved in this study are ignored. In addition, in endogenous variables, $\mathrm{HB}$ and $\mathrm{SB}$ are selected as representatives to study. In the previously investigated MSRB system, socially responsible behaviors, such as profitmaking behavior, compliance behavior, imitative behavior, and escape behavior, were reported [14]. The selection mechanism of these behaviors needs to be developed further.

Second, MSRB has interaction and dynamic evolution problems. This study explores the influence path relationship among subjects, MSRB, and situation. However, under the perspective of social responsibility behavior network, the interaction rules between behaviors have not been discussed in depth. For example, whether SB will promote imitative behavior and suppress HB is worthwhile to continue for indepth study and test. In addition, the issue of MSRB evolution under each phase of the project life cycle has yet to be resolved.

Third, the results of the study still require further empirical testing. This study adopts the exploratory PLS-SEM analysis method. After the later MSRB theory is gradually improved, sample size should be further expanded for 
confirmatory empirical research, and megaprojects under different types, management modes, and cultural and social environments need to be examined separately in accordance with their social responsibility characteristics. For instance, the research in this study is carried out in China, and its suitability is yet to be tested for the selection of MSRB in Western countries.

Finally, after determining the selection mechanism of the MSRB, the researchers can further develop MSRB method, behavioral performance measurement, MSRB performancedriven mechanism, explore the relationship between MSRB and megaproject project performance, and the differences in MSRB and different project types.

\section{Conclusion}

Good performance of MSR plays an active role in promoting economic development (for example, the Anglo-French tunnel promotes the integration process in Europe), eliminating social conflicts (for example, the Cologne Cathedral reduces religious conflicts), establishing a harmonious relationship between human and environmental ecology (for example, the Qinghai-Tibet Railway takes measures to protect wild animals), and implementing the concept of sustainable development (for example, the Moses Mabhida Stadium in South Africa considering the sustainability of urban regeneration) [3, 7]. Analyzing the social responsibility behavior selection mechanism of megaproject subjects provides theoretical guidance for various megaproject participants to fulfill their social responsibilities and helps behavior subjects make sound choices when encountering social responsibility issues in megaproject [14].

The selection of stakeholders toward MSRB is the decision and adjustment of how to fulfill their social responsibilities under the joint effect of internal characteristics of organization, interorganizational relationship, and external scenarios. In the megaproject, the behavioral subject in the face of social responsibility is the object of this study. On the basis of selection model of MSRB, this study verifies the impact of five influencing factors on the two types of social responsibility behaviors from three levels: intraorganization, interorganization, and situation. The empirical results reveal that under the background of major engineering social responsibility, not all choices of social responsibility behavior result from the combination of multiple factors but may also be the result of a specific factor of "catalysis." Hypocrisy is a form of alienated social responsibility behavior. This inconsistent behavior not only fails to achieve the goal of improving social welfare [53] but also creates the illusion of deceiving the public. SB is an interactive social responsibility behavior manifested by mutual support. This study considers these two typical social responsibility behaviors as an example to analyze the selection mechanism of MSRB. The results show that RQ has a significant driving effect on $\mathrm{HB}$ and has a significant inhibitory effect on HB. Effective MFM indirectly affects hypocritical behavior and coordinated behavior through the mediation variable RQ. This result confirms that ensuring the correct implementation of megaproject social responsibility requires the establishment of an effective MFM to enhance the quality of participant relationships. HB is affected by the constraints of the institutional norms and the influence of the supervision and appeal of the external public media. Therefore, advocating for the comprehensive management of behavioral subjects in megaprojects is necessary to actively respond to social responsibility behaviors from various aspects, such as institutions and relationships.

The empirical research on megaproject social responsibility in the past only focused on the behavioral performance and did not try to explore how the participating parties fulfill their social responsibility behaviors, that is, the way they behave. Although this study only examines the factors that influence the selection of two types of social responsibility behaviors, it illustrates the possibility of exploring the influencing factors of more social responsibility behavior selection from the perspective of social action theory. In addition, selection mechanisms of other different MSRB, interactions between different MSRB, and the dynamic evolution during the project life cycle have the value of being further explored. It is also worthwhile to verify the interpretation of MSRB selection by other behavior theories.

\section{Data Availability}

All data generated or used during the study are available in the supplementary materials.

\section{Disclosure}

The authors are solely responsible for the content.

\section{Conflicts of Interest}

The authors declare that they have no conflicts of interest.

\section{Acknowledgments}

The authors gratefully acknowledge the funding and support provided by the National Natural Science Foundation of China (NSFC) (Grant no. 71871096) and 2016 College International Research Cooperation "Seed Fund" from School of Civil Engineering and Transportation, South China University of Technology.

\section{Supplementary Materials}

The first file, titled "smartpls original data," is the original statistical data file for subsequent data analysis, obtained from the recycled questionnaires; and the another one, titled "megaproject social responsibility behavior Smartpls report," is the report exported by the statistical software "smartpls," used to analyze the hypothesis test results in the article. (Supplementary Materials)

\section{References}

[1] Z. Liu, Y. Sui, Z. Jin, and X. Yanf, "Evolution of major infrastructure project's social responsibility: from a global 
perspective," Journal of Systems and Management, vol. 27, no. 1, pp. 101-108, 2018, in Chinese.

[2] International Organization for Standardization, Guidance on Social Responsibility, International Organization for Standardization, Geneva, Switzerland, 2006.

[3] S. X. Zeng, H. Y. Ma, H. Lin, R. C. Zeng, and V. W. Y. Tam, "Social responsibility of major infrastructure projects in China," International Journal of Project Management, vol. 33, no. 3, pp. 537-548, 2015.

[4] L. Strauch, G. Takano, and M. Hordijk, "Mixed-use spaces and mixed social responses: popular resistance to a megaproject in Central Lima, Peru," Habitat International, vol. 45, pp. 177184, 2015.

[5] J. Korytarova, V. Hromadka, M. Radujković, M. Vukomanović, and R. Wagner, "The economic evaluation of megaprojects-social and economic impacts," Procedia-Social and Behavioral Sciences, vol. 119, pp. 495-502, 2014.

[6] R. Dyer, "Cultural sense-making integration into risk mitigation strategies towards megaproject success," International Journal of Project Management, vol. 35, no. 7, pp. 1338-1349, 2017.

[7] Z. Liu, L. Wang, Z. Sheng, and X. Gao, "Social responsibility in infrastructure mega-projects: a case study of ecological compensation for Sousa chinensis during the construction of the Hong Kong-Zhuhai-Macao Bridge," Frontiers of Engineering Management, vol. 5, 2018.

[8] H. Lin, S. Zeng, H. Ma, R. Zeng, and V. W. Y. Tam, “An indicator system for evaluating megaproject social responsibility," International Journal of Project Management, vol. 35, no. 7, pp. 1415-1426, 2017.

[9] X. Lin, C. M. F. Ho, and G. Q. P. Shen, "Who should take the responsibility? Stakeholders' power over social responsibility issues in construction projects," Journal of Cleaner Production, vol. 154, pp. 318-329, 2017.

[10] Z. Zhou and C. Mi, "Social responsibility research within the context of megaproject management: trends, gaps and opportunities," International Journal of Project Management, vol. 35, no. 7, pp. 1378-1390, 2017.

[11] G. Jia, F. Yang, G. Wang, B. Hong, and R. You, "A study of mega project from a perspective of social conflict theory," International Journal of Project Management, vol. 29, no. 7, pp. 817-827, 2011.

[12] C. Lee, W. W. Jin, W. Jang, W. Jung, S. H. Han, and Y. H. Kwak, "Social conflict management framework for project viability: case studies from Korean megaprojects," International Journal of Project Management, vol. 35, no. 8, pp. 1683-1696, 2017.

[13] X. Xue, R. Zhang, X. Zhang, R. J. Yang, and H. Li, "Environmental and social challenges for urban subway construction: an empirical study in China," International Journal of Project Management, vol. 33, no. 3, pp. 576-588, 2015.

[14] L. Xie, H. Chu, T. Han, and Y. Le, "Selection of megaproject social responsibility behavior based on social action theory," Journal of Civil Engineering and Management, vol. 35, no. 6, pp. 57-64, 2018, in Chinese.

[15] H. Kim, W. M. Hur, and J. Yeo, "Corporate brand trust as a mediator in the relationship between consumer perception of CSR, corporate hypocrisy, and corporate reputation," Sustainability-Basel, vol. 7, no. 4, pp. 3683-3694, 2015.

[16] H. Ma, S. Zeng, H. Lin, H. Chen, and J. J. Shi, "The societal governance of megaproject social responsibility," International Journal of Project Management, vol. 35, no. 7, pp. 1365-1377, 2017.
[17] P. A. Stanwick and S. D. Stanwick, The Relationship between Corporate Social Performance, and Organizational Size, Financial Performance, and Environmental Performance: An Empirical Examination, Springer, Netherlands, 2013.

[18] S. J. Yun, "Experts' social responsibility in the process of largescale nature-transforming national projects," Development and Society, vol. 43, no. 1, pp. 109-141, 2014.

[19] G. Y. Qi, L. Y. Shen, S. X. Zeng, and O. J. Jorge, "The drivers for contractors' green innovation: an industry perspective," Journal of Cleaner Production, vol. 18, no. 14, pp. 1358-1365, 2010.

[20] L. Liu and Z. F. Liang, The Study of Social Responsibility for Construction of Highway Engineering, in Proceedings of the 2008 Third International Conference on Convergence and Hybrid Information Technology, pp. 1031-1036, Busan, South Korea, November 2008.

[21] P. C. Liao, G. Tsenguun, and L. W. Liang, "Development of social responsibility evaluation framework of construction projects: a multi-stakeholders perspective," Procedia Engineering, vol. 145, pp. 234-241, 2016.

[22] T. P. Lyon and J. W. Maxwell, "Greenwash: corporate environmental disclosure under threat of audit," Journal of Economics \& Management Strategy, vol. 20, no. 1, pp. 3-41, 2011.

[23] A. La Cour and J. Kromann, "Euphemisms and hypocrisy in corporate philanthropy," Business Ethics: A European Review, vol. 20, no. 3, pp. 267-279, 2011.

[24] Z. Xian, Y. Lu, L. Yun, Y. Li, and J. Fang, "Formation of interorganizational relational behavior in megaprojects: perspective of the extended theory of planned behavior," Journal of Management in Engineering, vol. 34, no. 1, Article ID 4017052, 2018.

[25] D. Matten and J. Moon, "“Implicit" and "explicit” CSR: a conceptual framework for a comparative understanding of corporate social responsibility," Academy of Management Review, vol. 33, no. 2, pp. 404-424, 2008.

[26] C. Biesenthal, S. Clegg, A. Mahalingam, and S. Sankaran, "Applying institutional theories to managing megaprojects," International Journal of Project Management, vol. 36, no. 1, pp. 43-54, 2017.

[27] S. Jin, Z. Yang, and M. Qingfeng, "Evolutionary dynamics of firm's environmental compliance behavior under dynamic punishment," Journal of Systems and Management, vol. 26, no. 6, pp. 1122-1130, 2017, in Chinese.

[28] J. A. C. Baum and F. Dobbin, "The iron cage revisited: institutional isomorphism and collective rationality in organizational fields," American Sociological Review, vol. 48, no. 2, pp. 147-160, 1983.

[29] W. R. Scott, Institutions and Organizations: Ideas and Interests, Sage Publications, Los Angeles, CA, USA, 3rd edition, 2008

[30] G. Wang, Q. He, Y. Delei, X. Yan, and T. Yu, "Institutional pressures, organizational citizenship behaviors for the environment and environmental management performance: evidences from China's megaproject," Journal of Systems and Management, vol. 27, no. 1, pp. 118-128, 2018, in Chinese.

[31] A. Wang, "Information strategy for synergic megaproject social responsibility fulfillment and crisis management," Science and Technology Management Research, vol. 23, pp. 21-24, 2014.

[32] D. Holland, A. Krause, J. Provencher, and T. Seltzer, "Transparency tested: the influence of message features on public perceptions of organizational transparency," Public Relations Review, vol. 44, no. 2, pp. 256-264, 2017. 
[33] P. Williams, N. J. Ashill, E. Naumann, and E. Jackson, "Relationship quality and satisfaction: customer-perceived success factors for on-time projects," International Journal of Project Management, vol. 33, no. 8, pp. 1836-1850, 2015.

[34] H. L. Angle and J. L. Perry, "An empirical assessment of organizational commitment and organizational effectiveness," Administrative Science Quarterly, vol. 26, no. 1, pp. $1-14,1981$.

[35] A. Kadefors, "Trust in project relationships-inside the black box," International Journal of Project Management, vol. 22, no. 3, pp. 175-182, 2004.

[36] P. Naude and F. Buttle, "Assessing relationship quality," Industrial Marketing Management, vol. 29, no. 4, pp. 351-361, 2000.

[37] C. Black, A. Akintoye, and E. Fitzgerald, "An analysis of success factors and benefits of partnering in construction," International Journal of Project Management, vol. 18, no. 6, pp. 423-434, 2000.

[38] W. Lu and J. Wang, "The influence of conflict management styles on relationship quality: the moderating effect of the level of task conflict," International Journal of Project Management, vol. 35, no. 8, pp. 1483-1494, 2017.

[39] G. Wu, C. Liu, X. Zhao, and J. Zuo, "Investigating the relationship between communication-conflict interaction and project success among construction project teams," International Journal of Project Management, vol. 35, no. 8, pp. 1466-1482, 2017.

[40] B. Flyvbjerg, "What you should know about megaprojects and why: an overview," Project Management Journal, vol. 45, no. 2, pp. 6-19, 2014.

[41] Y. Hu, Y. Le, X. Gao, Y. Li, and M. Liu, "Grasping institutional complexity in infrastructure mega-projects through the multilevel governance system: a case study of the Hong KongZhuhai-Macao bridge construction," Frontiers of Engineering Management, vol. 5, no. 1, pp. 52-63, 2018.

[42] Y. Fassin, "The reasons behind non-ethical behaviour in business and entrepreneurship," Journal of Business Ethics, vol. 60, no. 3, pp. 265-279, 2005.

[43] M. Orlitzky and D. L. Swanson, "Corporate social and financial performance: an integrative review," Organization Studies, vol. 24, pp. 403-441, 2008.

[44] M. Fishbein and S. Middlestadt, "Noncognitive effects on attitude formation and change: fact or artifact?," Journal of Consumer Psychology, vol. 4, no. 2, pp. 181-202, 1995.

[45] T. Parsons, The Structure of Social Action, Free Press, New York, USA, 1980.

[46] H. Lin, Y. Sui, H. Ma, L. Wang, and S. Zeng, "CEO narcissism, public concern, and megaproject social responsibility: moderated mediating examination," Journal of Management in Engineering, vol. 34, no. 4, Article ID 04018018, 2018.

[47] G. Wang, Q. He, X. Meng, G. Locatelli, T. Yu, and X. Yan, "Exploring the impact of megaproject environmental responsibility on organizational citizenship behaviors for the environment: a social identity perspective," International Journal of Project Management, vol. 35, no. 7, pp. 1402-1414, 2017.

[48] H. Zheng, On the Behavior of Corporate Social Responsibility: Dimensions, Determinants, and Impact on Business Performance, Zhejiang University, Hangzhou, China, 2007, in Chinese.

[49] J. Xu and Y. Ren, "An empirical study on project relationship quality, project performance and their impact relationship," Forecasting, vol. 29, no. 1, pp. 71-75, 2010, in Chinese.
[50] H. Zhao, "A study of the driving factors of enterprises' pseudo-social responsibility behaviors," Contemporary Finance and Economics, vol. 35, no. 12, pp. 77-86, 2014, in Chinese.

[51] Y. Hua, J. Tao, and J. Yang, "The impact of corporate social responsibility performance on employee loyalty," Enterprise Economy, vol. 34, no. 5, pp. 51-55, 2014, in Chinese.

[52] T. Wagner, R. J. Lutz, and B. A. Weitz, "Corporate hypocrisy: overcoming the threat of inconsistent corporate social responsibility perceptions," Journal of Marketing, vol. 73, no. 6, pp. 77-91, 2009.

[53] H. Xiao, J. Zhang, and W. Li, "Research on the behaviors of pseudo-CSR," China Industrial Economics, vol. 27, no. 6, pp. 109-121, 2013, in Chinese.

[54] M. Yan, L. Yan, and J. Deng, "Industry practice, relational norms and cooperative behavior: a study based on construction project organizations," East China Economic Management, vol. 29, no. 8, pp. 165-174, 2015, in Chinese.

[55] J. F. Hair, W. C. Black, B. J. Babin, and R. E. Anderson, Multivariate Data Analysis: A Global Perspective, Pearson Education, London, UK, 2010.

[56] J. F. Hair, C. M. Ringle, and M. Sarstedt, "PLS-SEM: indeed a silver bullet," Journal of Marketing Theory and Practice, vol. 19, no. 2, pp. 139-152, 2011.

[57] M. E. Drumwright, "Socially responsible organizational buying: environmental concern as a noneconomic buying criterion," Journal of Marketing, vol. 58, no. 3, pp. 1-19, 1994.

[58] L. $\mathrm{Zu}$ and L. Song, "Determinants of managerial values on corporate social responsibility: evidence from China," Journal of Business Ethics, vol. 88, no. S1, pp. 105-117, 2009. 


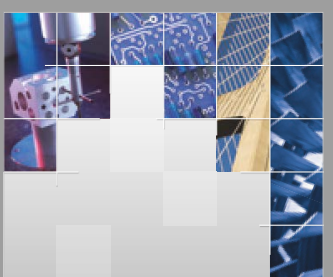

\section{Enfincering}
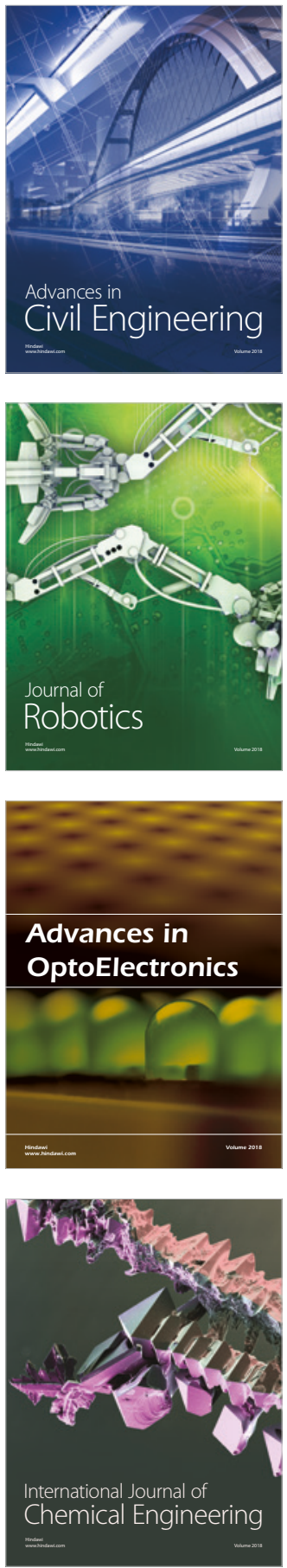

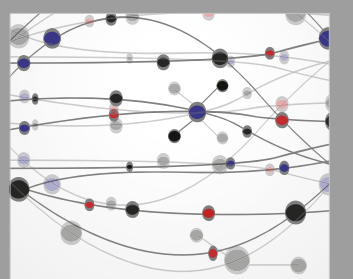

\section{Rotating \\ Machinery}

The Scientific World Journal

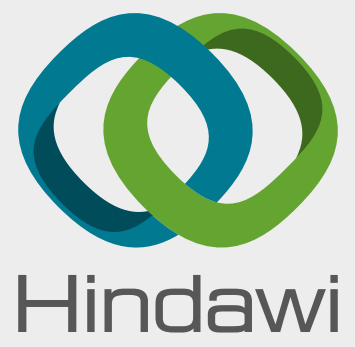

Submit your manuscripts at

www.hindawi.com
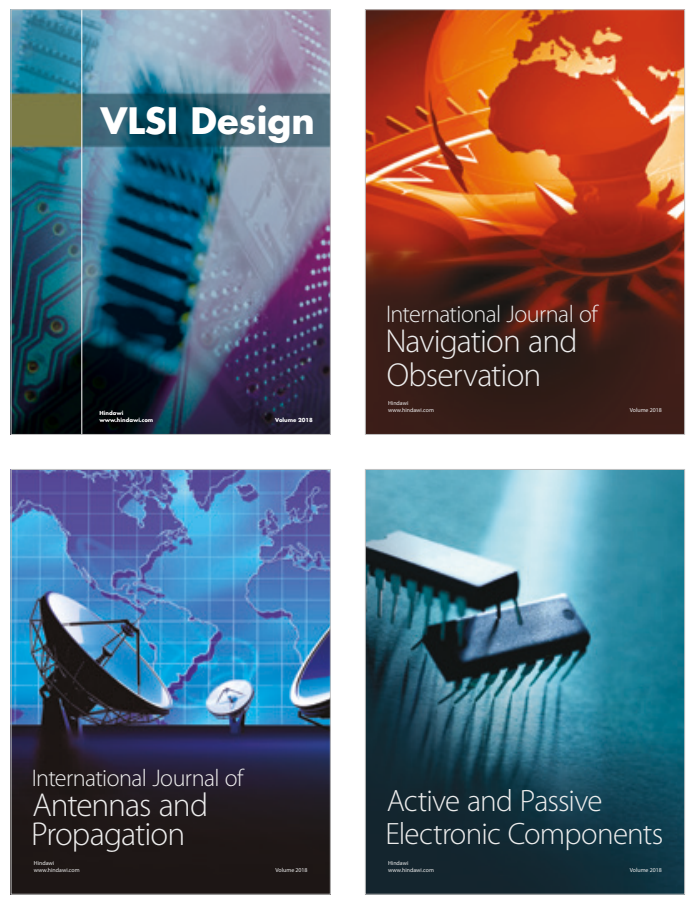
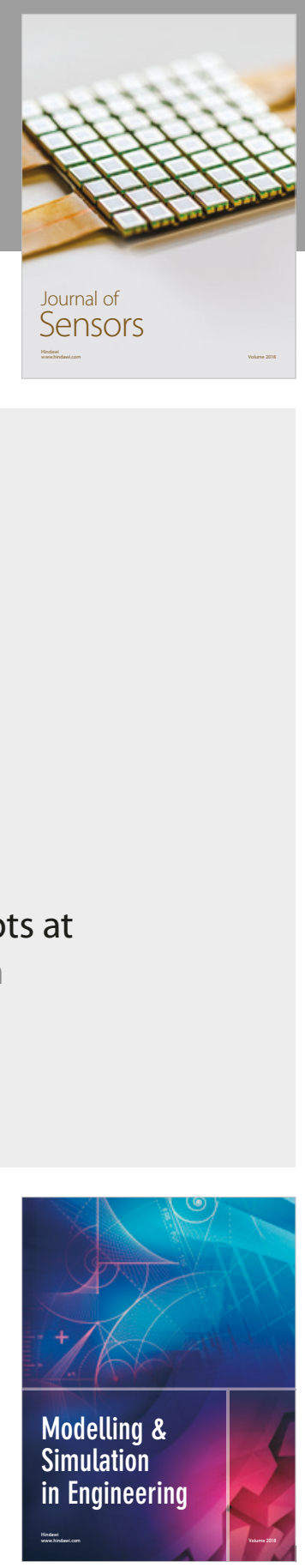

\section{Advances \\ Multimedia}
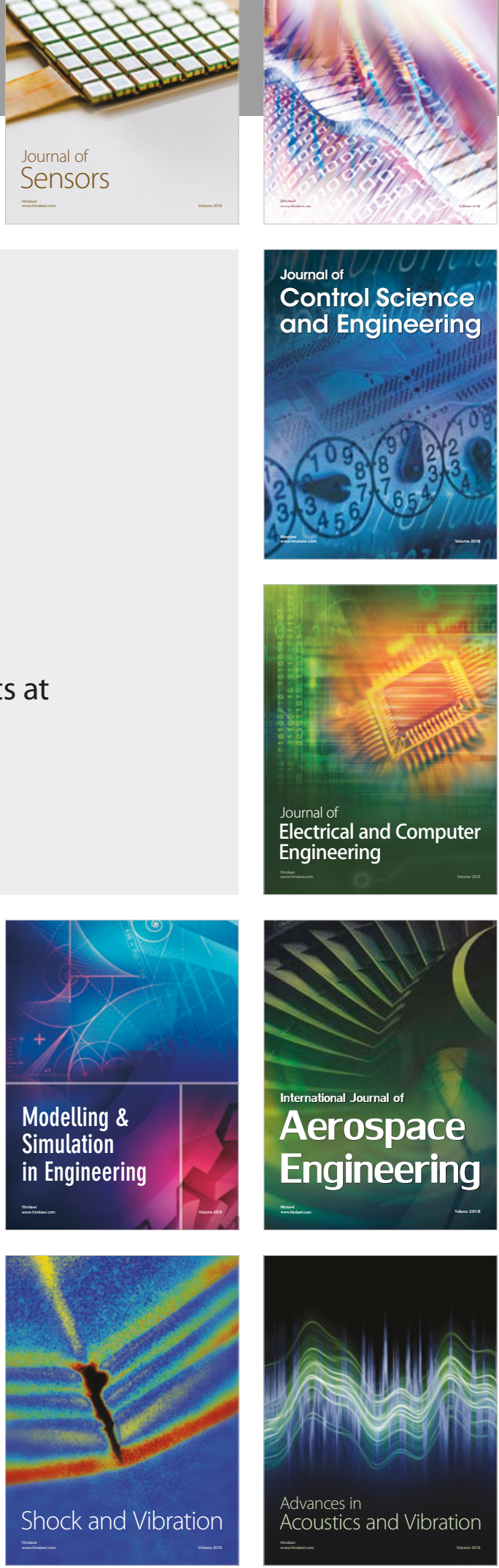